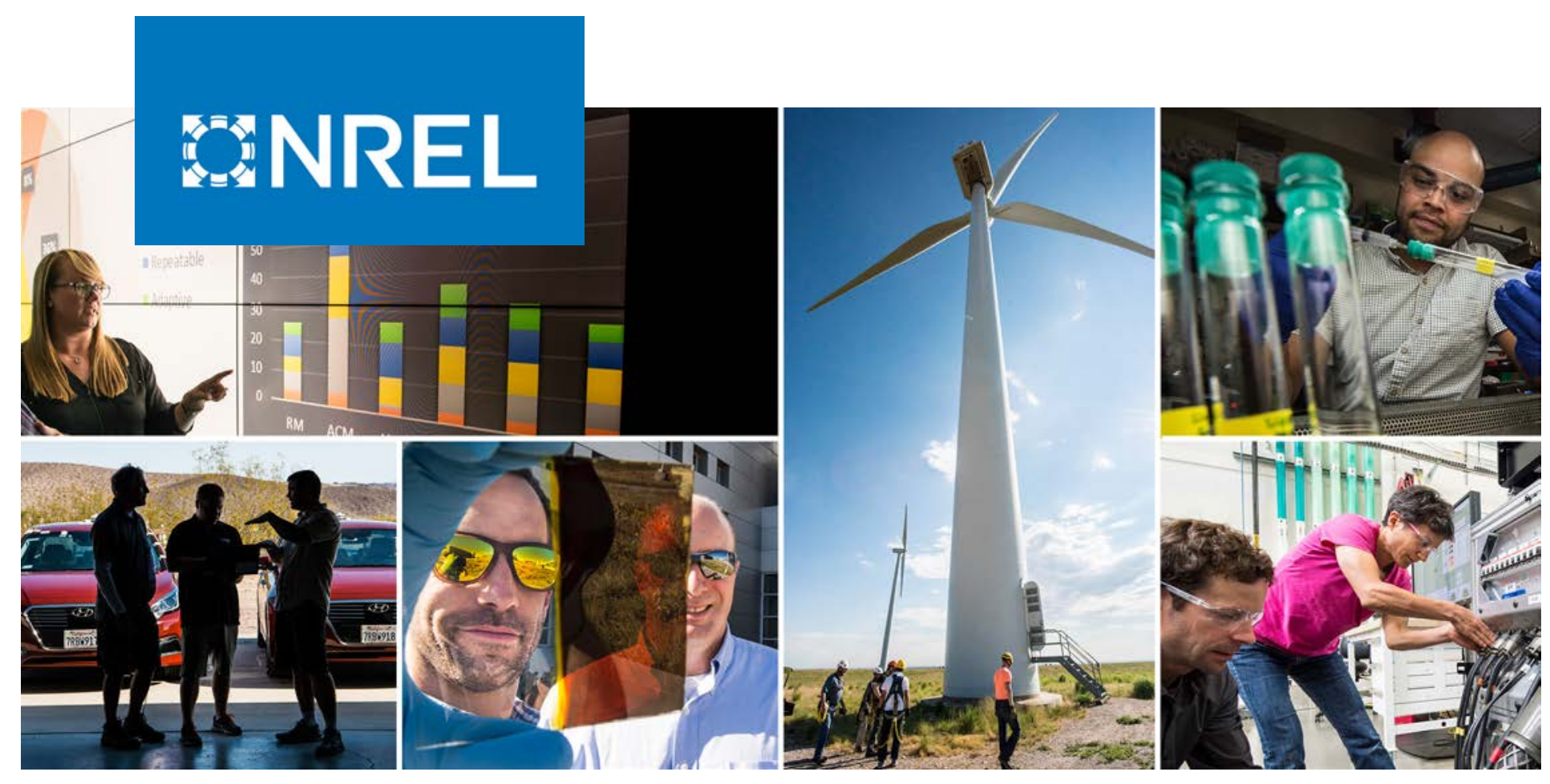

\title{
Guidelines for Home Energy Professionals: Standard Work Specifications (SWS) Maintenance Charter and Procedures
}

Charles Kurnik, Zachary Peterson, and David Lovullo

National Renewable Energy Laboratory

NREL is a national laboratory of the U.S. Department of Energy Office of Energy Efficiency \& Renewable Energy

Operated by the Alliance for Sustainable Energy, LLC

This report is available at no cost from the National Renewable Energy Laboratory (NREL) at www.nrel.gov/publications.

\section{Technical Report}

NREL/TP-7A40-75970

February 2020 


\title{
GNREL
}

\section{Guidelines for Home Energy Professionals: Standard Work Specifications (SWS) Maintenance Charter and Procedures}

\author{
Charles Kurnik, Zachary Peterson, and David Lovullo
}

National Renewable Energy Laboratory

\section{Suggested Citation}

Kurnik, Charles, Zachary Peterson, and David Lovullo. 2020. Guidelines for Homes Energy Professionals: Standard Work Specifications (SWS) Maintenance Charter and Procedures. Golden, CO: National Renewable Energy Laboratory. NREL/TP-7A40-75970.

https://www.nrel.gov/docs/fy20osti/75970.pdf.

NREL is a national laboratory of the U.S. Department of Energy Office of Energy Efficiency \& Renewable Energy Operated by the Alliance for Sustainable Energy, LLC

This report is available at no cost from the National Renewable Energy Laboratory (NREL) at www.nrel.gov/publications.

Contract No. DE-AC36-08GO28308
Technical Report NREL/TP-7A40-75970 February 2020

National Renewable Energy Laboratory 15013 Denver West Parkway Golden, CO 80401 303-275-3000 • www.nrel.gov 


\section{NOTICE}

This work was authored by the National Renewable Energy Laboratory, operated by Alliance for Sustainable Energy, LLC, for the U.S. Department of Energy (DOE) under Contract No. DE-AC36-08GO28308. Funding provided by U.S. Department of Energy Office of Energy Efficiency and Renewable Energy Weatherization and Intergovernmental Programs Office. The views expressed herein do not necessarily represent the views of the DOE or the U.S. Government.

This report is available at no cost from the National Renewable Energy Laboratory (NREL) at www.nrel.gov/publications.

U.S. Department of Energy (DOE) reports produced after 1991 and a growing number of pre-1991 documents are available free via www.OSTI.gov.

Cover Photos by Dennis Schroeder: (clockwise, left to right) NREL 51934, NREL 45897, NREL 42160, NREL 45891, NREL 48097, NREL 46526.

NREL prints on paper that contains recycled content. 


\section{List of Acronyms}

DOE

GHEP

HVAC

$\mathrm{MF}$

$\mathrm{MH}$

NREL

SBH

SME

SWS

WAP
U.S. Department of Energy

Guidelines for Home Energy Professionals

Heating, Ventilation, and Air Conditioning

multifamily

manufactured housing

National Renewable Energy Laboratory

site-built housing

subject matter expert

Standard Work Specifications

Weatherization Assistance Program 


\section{Table of Contents}

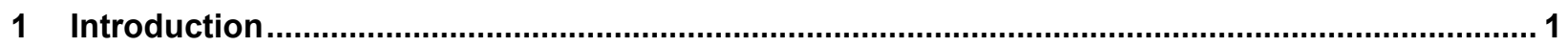

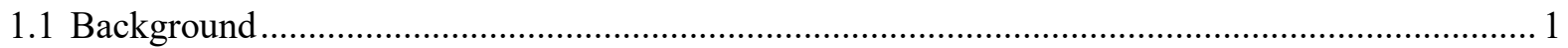

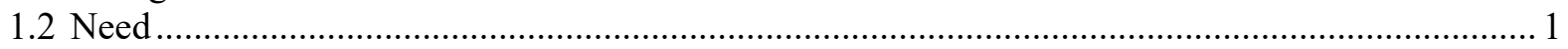

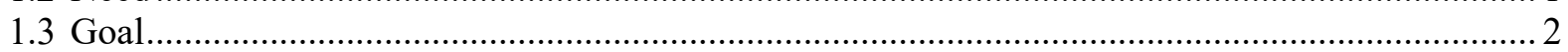

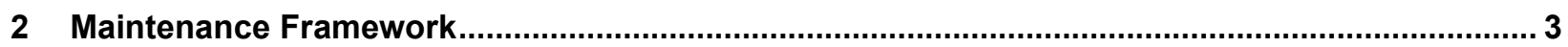

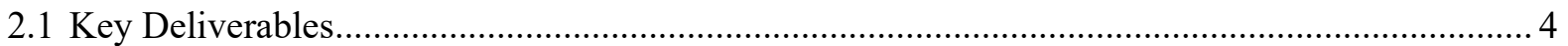

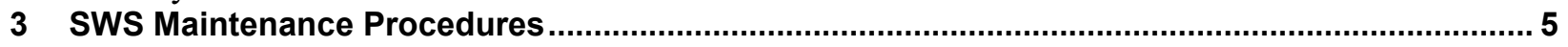

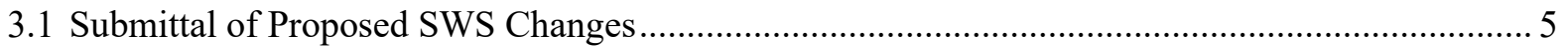

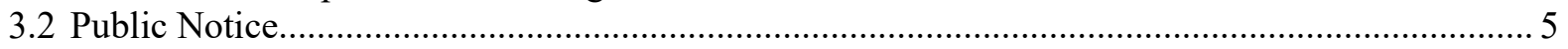

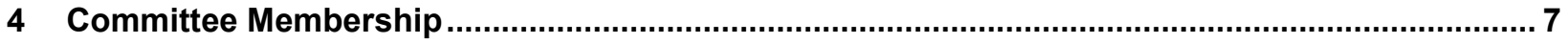

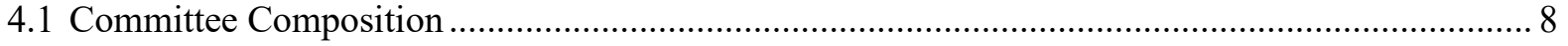

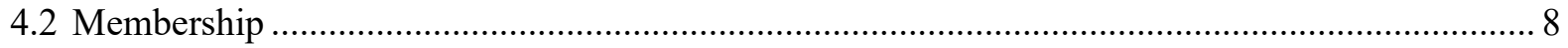

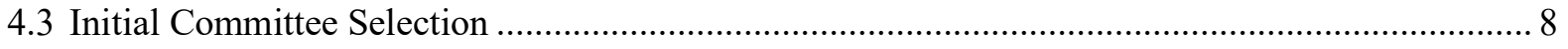

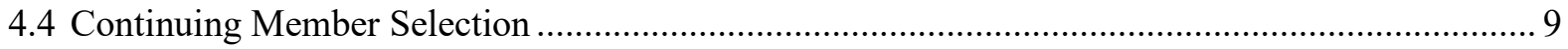

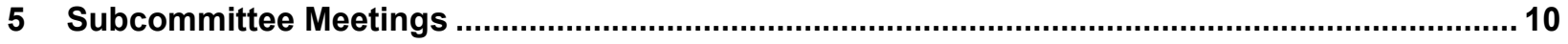

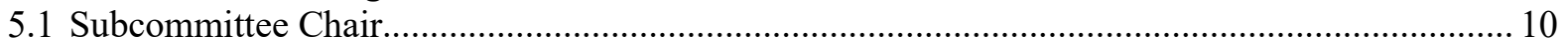

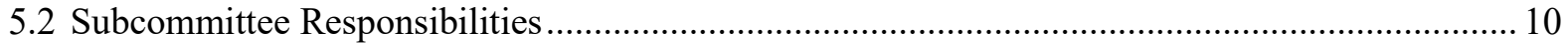

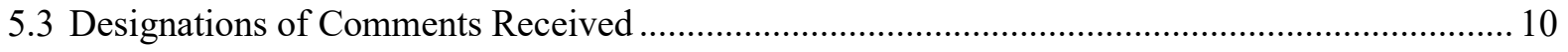



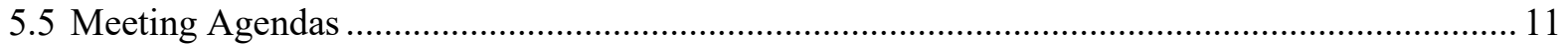

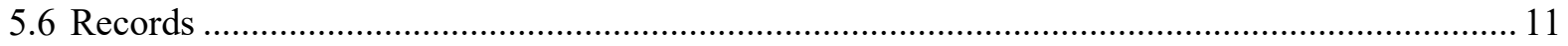

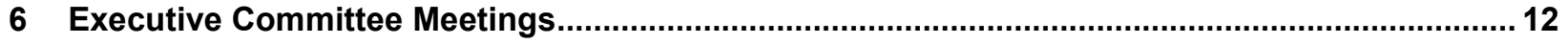

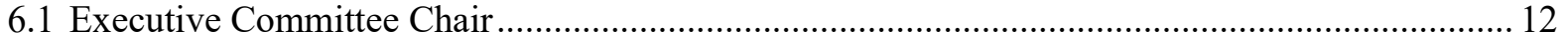

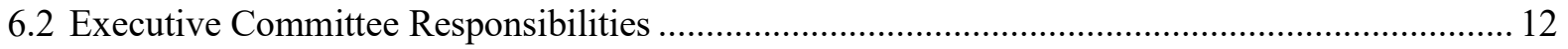

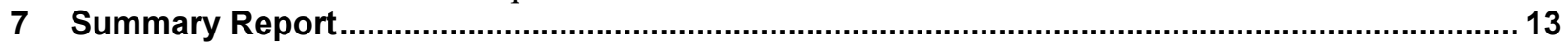

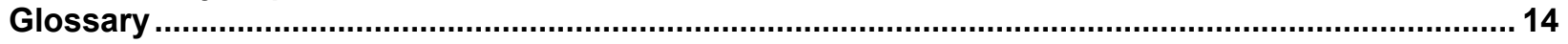

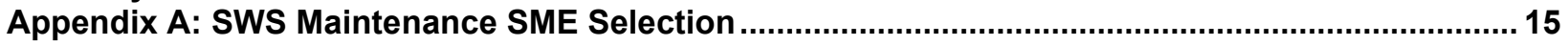

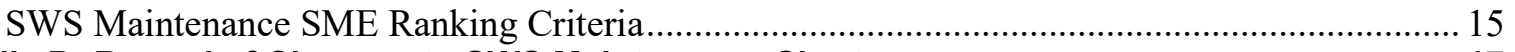

Appendix B: Record of Changes to SWS Maintenance Charter ................................................. 17 


\section{List of Figures}

Figure 1. Five-year adjudication cycle 3

Figure 2. SWS maintenance procedures overview............................................................................ 5

Figure 3. SWS maintenance committee organization ........................................................................ 7

\section{List of Tables}

Table B- 1. Record of Changes to SWS Maintenance Charter .................................................... 17 


\section{Introduction}

\subsection{Background}

The U.S. Department of Energy (DOE) Weatherization Assistance Program (WAP) and DOE's National Renewable Energy Laboratory (NREL) established the Guidelines for Home Energy Professionals (GHEP) project to support and promote high-quality work within the weatherization and home energy upgrade or home performance industry, based on the wholehouse approach to energy efficiency. A primary objective of the GHEP project is to create highquality workforce guidelines in accordance with industry best practices. These guidelines help practitioners to effectively optimize the use of taxpayer investment and improve realized efficiency outcomes for low-income Americans participating in the WAP program. While focused on the WAP constituents, GHEP use has the potential to improve weatherization outcomes across efficiency programs.

One of the major components of this GHEP effort is to define work through voluntary Standard Work Specifications (SWS) for single-family-site built, multifamily, and manufactured housing energy upgrades. The SWS represent consensus-based guidance developed in accordance with industry best practices and intended to achieve higher-quality outcomes for home weatherization. Collaboration with industry throughout the SWS development process ensures consensus across the WAP network and private industry. This collaboration is accomplished through the involvement of public, private, and federal sector subject matter experts (SME). Feedback is obtained through a multistage, iterative process and stakeholder engagement. This document describes the methodology for maintaining the SWS.

\subsection{Need}

As the weatherization industry advances, the SWS must be maintained to ensure they continue to reflect industry-accepted practices. The SWS are periodically reviewed to capture current best practices recommended by the community, as well as to promote consistency across the industry, including training centers and GHEP-certifying bodies. Maintenance of the SWS necessitates the active engagement of industry to instill confidence, thereby increasing consumer demand for high-quality home energy efficiency retrofits. Continuing to provide a consensus-based centralized resource of current industry-accepted practices and a consensus-based revision process provides the best potential outcomes for the SWS.

In addition, one of the requirements of the WAP's Quality Work Plan is that each WAP grantee develops a field guide based on the desired outcomes of the SWS. This field guide is used to implement WAP-funded work that aligns with the content in the SWS. Each time the SWS is updated, Grantees are required to revise their field guides accordingly. ${ }^{1}$ Thus, the SWS have become a critical component of the WAP. The SWS maintenance historically occurred on a three-year cycle in which an industry-comprised SWS maintenance committee met annually to revise the SWS to align with current standards and practices. In 2020, the SWS transitions to a five-year maintenance cycle, reflecting the maturity of the SWS. Updating the SWS every five years reduces the burden on the grantees required to revise their field guides. By maintaining the SWS in this fashion, the WAP will continue to serve as the industry model and demonstrate the

\footnotetext{
${ }^{1}$ This refers to a SWS update rather than a redline. This is described more in Section 3.
} 
WAP's commitment to achieving high-quality work, safety, and effective use of taxpayer dollars.

\subsection{Goal}

The SWS were built by industry, for industry, and DOE and NREL facilitated the process to create them. The goal of the SWS maintenance process is to continue the consensus-based engagement to ensure the SWS content remains a relevant resource for promoting industryaccepted practices and maintaining consistency throughout the industry. This SWS Maintenance Charter and Procedures document defines the SWS maintenance process to provide transparency to stakeholders in how the SWS are maintained.

The remaining sections of the document are organized as follows:

- Section 2 outlines the maintenance framework and provides a structure to transition ownership of the SWS to the WAP network and home performance industry, as well as inform the certification scheme committee of SWS revisions that may affect the GHEP certifications;

- Section 3 provides an overview of how changes to the SWS are submitted and reviewed, as well as how stakeholders are kept informed of changes;

- Section 4 describes how the SWS maintenance committees are organized, their composition, and member selection;

- Section 5 discusses the responsibilities of subcommittee members, as well as logistics for subcommittee meetings and voting;

- Section 6 defines the responsibilities and expectations for the executive committee; and

- Section 7 provides the requirements for the Summary Report created following a maintenance event. 


\section{Maintenance Framework}

The SWS maintenance process is primarily driven by comments received from stakeholders. These comments can be made at any point in time via the SWS online tool. The SWS maintenance committees periodically review publicly submitted comments and discuss recommended changes to the SWS technical content. NREL coordinates the SWS maintenance committee meetings and assists with the transition of the SWS content ownership to the WAP network and industry practitioners as needed. NREL ensures all comments are reviewed and the SWS is revised through a consensus-based process.

Figure 1 shows a simple illustration of the five-year maintenance cycle. During years one and two, public comments on the most recent SWS will be collected. In the beginning of year three, NREL will coordinate the review of submitted comments on the SWS with the SWS maintenance committees. The SWS maintenance committees will review and adjudicate all comments and create a redline of the SWS. The redline is used to communicate forthcoming changes to the SWS and provide stakeholders an opportunity to respond to forthcoming changes. Only one redline will be produced during the five-year cycle. This redline will be published by the end of year three. In year four, public comments on the redlined SWS will be collected. In the fifth and final year, the SWS committees will review and adjudicate public comments received for the redline in year four. A revised version of the SWS will be produced and published by the end of year five. This cycle will repeat starting the following year.

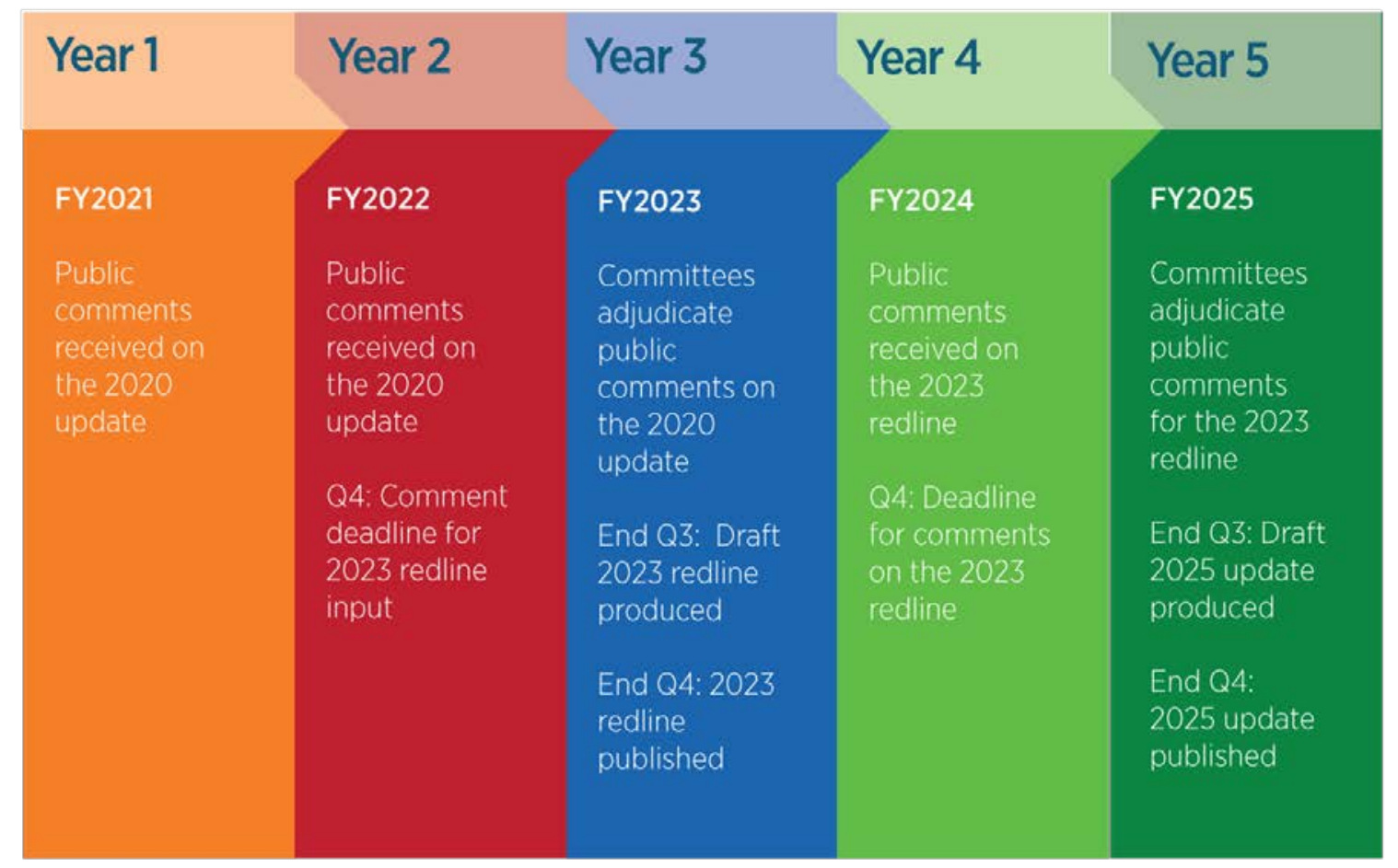

Figure 1. Five-year adjudication cycle 


\subsection{Key Deliverables}

The key deliverables from the SWS maintenance activities are divided by responsibility. The subcommittee documents each comment, the subcommittee's adjudication, and any proposed new language. The subcommittee may submit a list of requests for enhancements to the SWS online tool, additional SWS details, major changes to the SWS, or it may request to complete a full code review per section.

The executive committee delivers a summary of recommended revisions to the SWS Maintenance Charter and Procedures document, addresses crosscutting issues, and recommends public statements. The facilitator, NREL, ensures all comments are adjudicated during a maintenance event, and responses and proposed new language are complete. Any meeting minutes from subcommittee or executive committees will be completed by the facilitator.

A summary report is delivered to DOE that includes an attendee list, major decisions, lessons learned, and a list of all changes to the SWS. The report is made available to industry through the SWS online tool. Accepted changes are made as revisions within the SWS online tool. NREL determines the impact to the Job Task Analysis and certification schemes based on the comment adjudication and additional requests, the executive summary of changes, and the summary report as certifications are based on the SWS. NREL will deliver the revised SWS within the SWS online tool, based on accepted changes. 


\section{SWS Maintenance Procedures}

\subsection{Submittal of Proposed SWS Changes}

Proposed changes to the SWS must be submitted by the public via the SWS online tool at sws.nrel.gov. Specific changes in text or values are required and must be substantiated. Supplemental background documents to support changes submitted may be included in Microsoft Word, Microsoft Excel, Microsoft PowerPoint, or PDF format. Upon receipt of a comment, an automated response is generated by the system, providing information regarding the review process, timeline, and when to expect SWS updates.

Comments are not made public before the maintenance event. All comments, along with comment resolution and any applicable reasoning, will be published within 90 days after the maintenance event and updated in the SWS. If comments are rejected by the committee, appeals can be made by submitting a new comment to the SWS online tool in opposition. A deadline for comments for each maintenance event is posted on the SWS online tool 30 days prior.

Comments made after a posted deadline may not be adjudicated until the following maintenance event.

Before the maintenance event, the facilitator (NREL) will work with subcommittee chairs to prepare for facilitating the meetings, including organizing comments and assigning each comment to a subcommittee. Figure 2 shows the SWS maintenance process for maintenance events and SWS updates.

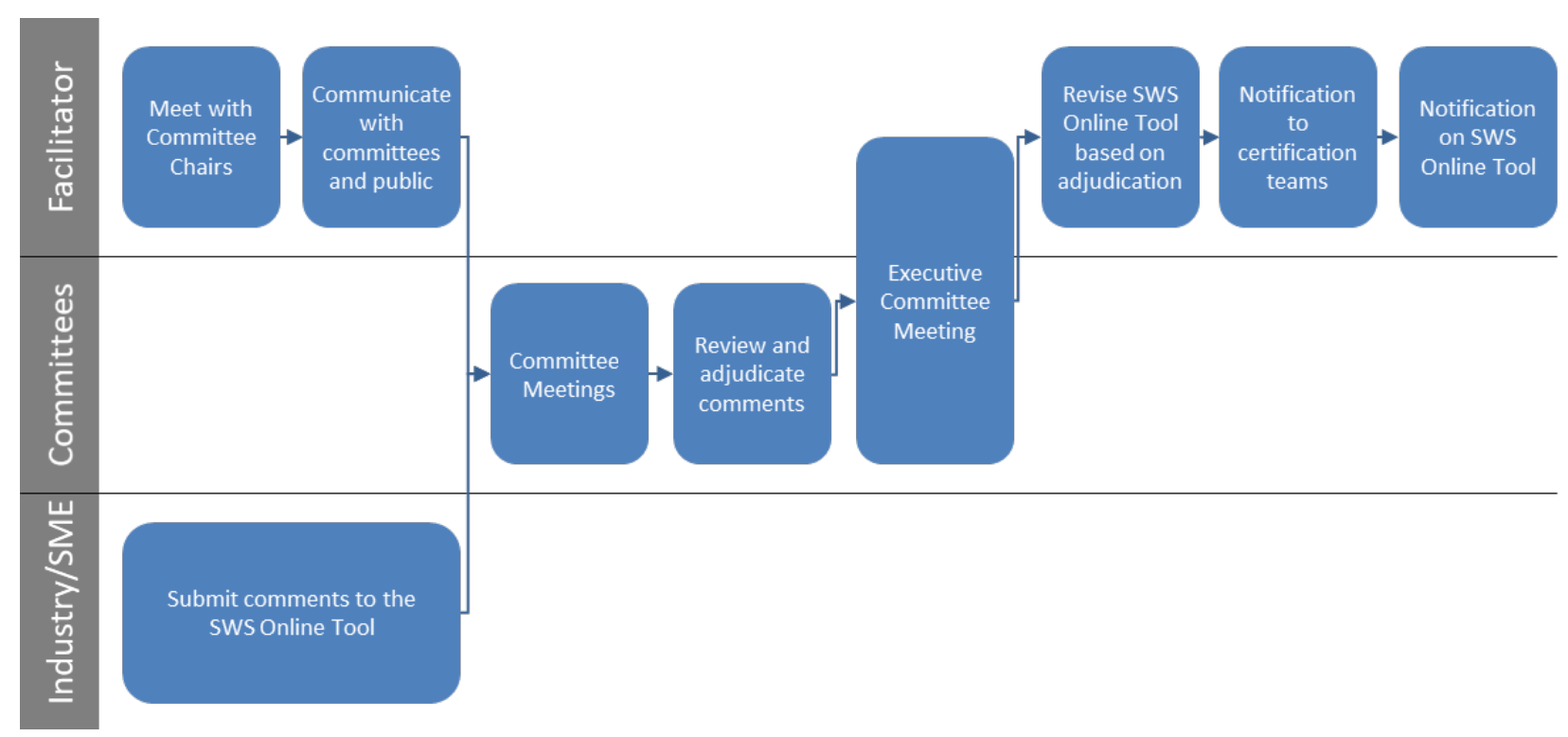

Figure 2. SWS maintenance procedures overview

\subsection{Public Notice}

Timely and adequate notice of in-person SWS maintenance events shall be posted as a news item on the SWS website 60 days prior to the event. Notices should include a clear and meaningful description of the purpose of the proposed activity. In addition, outreach emails to user groups will be sent 60 days prior to an event. 
In-person subcommittee and executive committee meetings are open to the public. Attendees may only participate during open times or as requested by the subcommittee chair or executive committee chair. 


\section{Committee Membership}

The maintenances committees are composed of one executive committee and three subcommittees. The executive committee includes the chairpersons of the three subcommittees, as well as DOE and DOE-appointed subcontractors. The subcommittees are broken into the SWS sections: Health \& Safety, Air Sealing \& Insulation, and Heating, Ventilation, Air Conditioning (HVAC) \& Baseload. For the breakdown, major topic areas are grouped together with singlefamily-site-built housing ( $\mathrm{SBH})$, manufactured housing $(\mathrm{MH})$, and multifamily (MF) housing being addressed by the same subcommittee. The SBH and MH SWS have similar content, while the MF may vary because of unique building characteristics. Figure 3 shows the organization of the subcommittees by housing type and topic area.

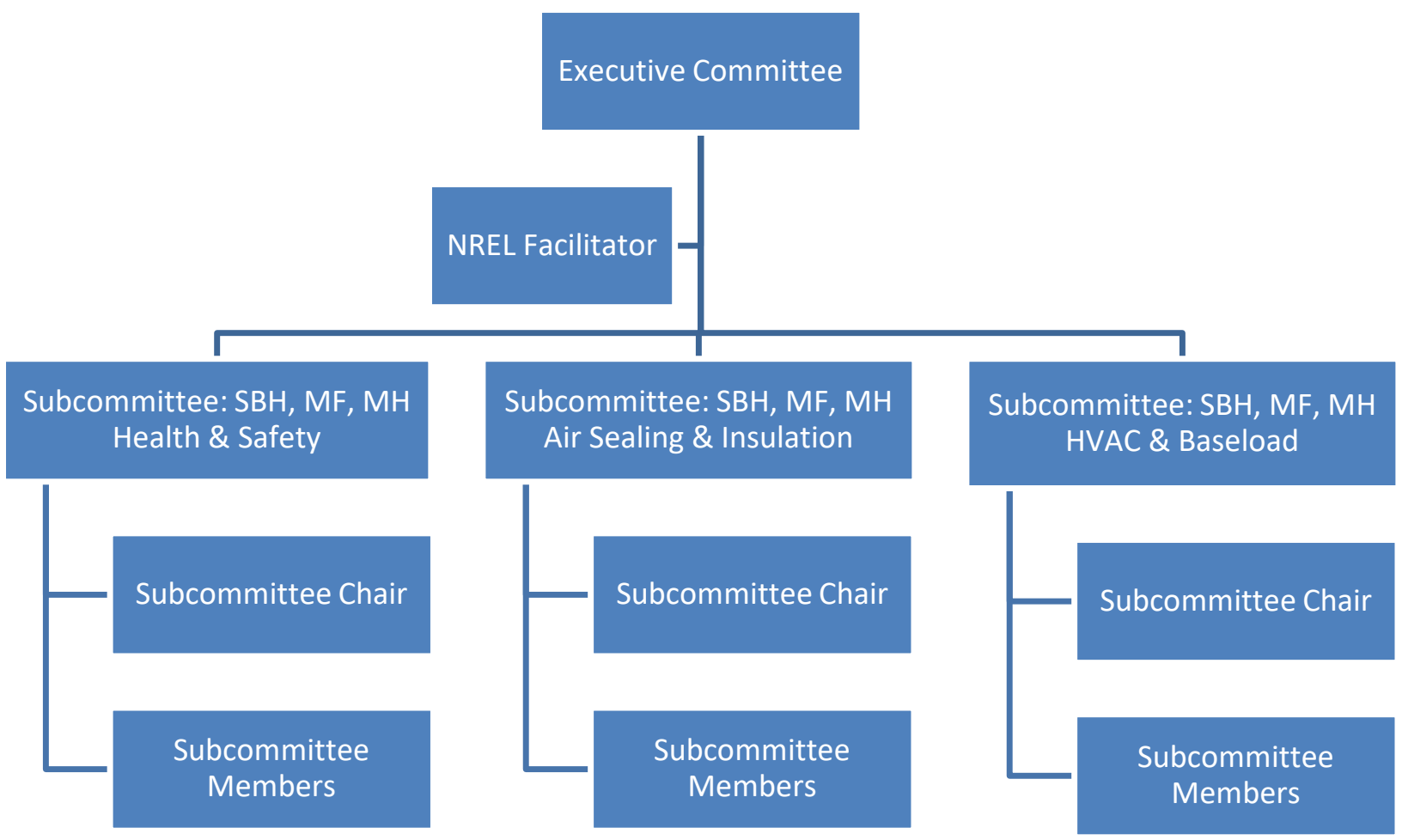

Figure 3. SWS maintenance committee organization

Before the maintenance event, the SWS facilitator (NREL), works with the executive committee to prepare for the executive committee and subcommittee meeting discussions. NREL organizes comments to adjudicate and facilitates committee discussions as these comments are addressed.

The subcommittees function as the working group for adjudicating comments received on the SWS, specifically those comments received during the comment review period prior to the SWS maintenance event. Subcommittee members will discuss and designate a response to each comment received. The subcommittees are responsible for revising the technical content of each section of the SWS and relevant addenda.

For an in-person maintenance event, the executive committee convenes directly following the subcommittee meetings to summarize actions to be taken and discuss major crosscutting issues in the SWS. During webinar-based maintenance events, the executive committee meets within 30 
days following the last subcommittee meeting. The executive committee can also vote to revise future maintenance processes for the SWS to increase its efficiency, effectiveness, or its scope according to input from subcommittee members.

\subsection{Committee Composition}

The subcommittees shall consist of no fewer than three or more than 12 persons each, including the subcommittee chair, based on best practices of small working groups. The executive committee shall consist of the three subcommittee chairs. A DOE WAP staff member shall sit in on the executive committee meeting as an adviser. DOE may appoint an additional technical expert to the executive committee. NREL shall facilitate all meetings.

Balance shall be maintained within the membership of the committees. Unless it is claimed in writing (including electronic communications) by a directly and materially affected party that a single interest category, individual, or organization has dominated the SWS development or maintenance process, no test for dominance is required. If balance is not maintained, the executive committee members and DOE representatives shall propose a solution.

\subsection{Membership}

The executive committee may remove any member of the committees for due cause. The executive committee will consider removal after receiving a petition from more than $50 \%$ of the members of the subcommittee or the executive committee. Failure to return virtual voting may be considered a cause for removal. Termination may be enacted only by a vote of at least $75 \%$ of the executive committee at a duly called and convened (in-person or virtual) meeting. The affected member or representative shall receive 30 days written notice from the executive committee prior to such a meeting. The decision of the executive committee regarding a member or representative's termination shall be conclusive. The affected member shall be notified within five days of any executive committee decision in writing.

The facilitator of the SWS maintenance event and all committee members shall not discriminate among persons based on age, gender, race, religion, national origin, disability, marital status, or sexual orientation.

Terms of the subcommittee chairs shall be for one SWS maintenance event, with the option to continue, provided committee members do not object. Terms shall commence at the next SWS maintenance event after the chair has been selected. All members are responsible for participating in meetings. Failure to participate in three or more meetings may result in termination of service.

During a term, only one person from an organization, excluding DOE on the executive committee, may serve on the executive committee. During a term, no more than two persons from an organization may serve on each subcommittee.

\subsection{Initial Committee Selection}

Subcommittee members are selected by subcommittee chairs, NREL and DOE staff facilitate and participate in SWS maintenance events. Subcommittee chairs are nominated and voted on by subcommittee members. The selection process begins with a "call for members" announcement. 
Subcommittee members may nominate candidates. Drawing from the resulting applications and nominations, candidate subcommittee members are recommended in consideration of their subject matter expertise and their effect on subcommittee balance. Recommended members are approved or disapproved by DOE. Selection of the executive committee chair takes place along with the recommendation of the other subcommittee members.

Committee chairs will show previous experience supporting the SWS (creation event, commenter, early adopter, and so on). Applicants are not required to have obtained a Home Energy Professionals Certification, but it is preferable. Chairs must demonstrate facilitation, organization, and/or leadership experience. Additionally, chairs will need to commit to supporting at least one maintenance event. Ranking criteria for committee selection can be found in Appendix A.

Honoraria of \$1,000 will be provided to subcommittee chairs only. Letters of appreciation from DOE/NREL will be available for chairs and members for their employers to encourage participation.

\subsection{Continuing Member Selection}

Subcommittee chairs will serve for at least one maintenance event. When the chair has facilitated one event or notifies the members that the chair will be vacating the position, the members will have the opportunity to nominate and vote for a new chair. Voting will follow the procedures outlined in Section 5.4. All chairs must receive approval by DOE. Chairs must be selected 30 days prior to upcoming maintenance events.

If a vacancy occurs within a subcommittee, the current membership of the committee should first draw from consistent public attendees, past committee applicants or by recommendation from current subcommittee members. Candidates may be considered from the broader public if there is difficulty identifying eligible candidates. Replacement subcommittee members shall be selected based on their subject matter expertise and their effect on subcommittee balance. Candidate are approved or disapproved by DOE.

If a vacancy occurs for the executive committee chair, the current executive committee membership should draw from the existing subcommittee chairs and then from consistent attendees. The recommended executive committee chair is approved by a majority vote of current subcommittee members. 


\section{Subcommittee Meetings}

The subcommittee meeting is the working group for adjudicating comments received in the designated comment period. The subcommittees shall meet at a minimum, two times during each five-year maintenance cycle. One meeting shall be an in-person meeting, and one may be inperson or virtual. Additional meetings may be called by the executive committee chair by majority vote of the executive committee or by the facilitator.

\subsection{Subcommittee Chair}

Each subcommittee shall have one chairperson. The subcommittee chair shall serve as the principal spokesperson for the subcommittee and shall preside at all meetings of the subcommittee. The chair verifies the review and approval of all reports, adjudication results, and other documents from the subcommittee meetings.

\subsection{Subcommittee Responsibilities}

A subcommittee will review each comment submitted. Any subcommittee member may propose language to address the comment and request that a vote be taken to implement the change in the SWS. The facilitating organization will provide a scribe for each subcommittee meeting.

The responsibilities of the subcommittee are to:

- Review each comment submitted to the section

- Provide a response to each submitted comment

- Record adjudications to each comment

- Propose new language to the SWS

- Recommend enhancements to the SWS online tool

- Recommend additional details or major changes to the SWS

- Recommend code reviews as needed

- Recommend topics of discussion for the executive committee as applicable

- Confirm existing chair or select chair moving forward

- Ensure meeting minutes are recorded and sent to the executive committee.

\subsection{Designations of Comments Received}

In the subcommittee meeting, members shall discuss and designate each comment received as:

- Accepted-Comment accepted as suggested by the commenter;

- Accepted with modification-Comment accepted with some modification of what was submitted by the commenter;

- Further investigation required-Acceptance or rejection of the comment is pending as the issue receives further investigation; and

- Rejected-Comment rejected by the committee. 
The committee responses shall also provide reasons for any recommendation other than "Accepted." If further investigation is required, the investigation must be completed within 90 days of the conclusion of a maintenance event.

\subsection{Quorum and Voting Requirements}

The transaction of all business shall be governed by Robert's Rules of Order (latest edition) unless otherwise set forth herein.

A quorum must be present to conduct business at a meeting of a subcommittee or the executive committee. A quorum exists if a majority of the voting membership is present. When all members are physically present in the same location, the majority opinion (greater than $50 \%$ of subcommittee members) decides the vote at hand. When all members are not physically present in the same location, voting may be conducted electronically via email or other electronic means.

\subsection{Meeting Agendas}

Meeting agendas shall follow this approximate outline:

1. Call to order by the subcommittee chair or presiding member

2. Approval of agenda

3. Consideration, correction, and approval of minutes of the previous meeting

4. Review of SWS comments

5. Review of cross-cutting issues

6. Review of policy and procedure changes

7. Unfinished business

8. New business

9. Adjournment.

\subsection{Records}

Records shall be maintained to provide evidence of the process. Records shall be retained by the facilitator for a minimum of one complete maintenance event or five years. Records consist of the adjudicated comment spreadsheets and the maintenance report that is produced after each inperson meeting. 


\section{Executive Committee Meetings}

The executive committee shall be convened at the end of all the subcommittee meetings to bring all the subcommittee chairs and facilitators together to provide a summary of actions taken and to discuss major overarching issues in the SWS. The facilitator will oversee the meeting of the chairs. A member of NREL's Home Energy Professional certification team may participate to relay actions taken by the SWS executive committee back to the certification team.

DOE will have the opportunity to review the responses to comments prior to posting to ensure consistency in the WAP policies and program. Proposed amendments to any section of the SWS Maintenance Procedures may be approved by a majority vote of the executive committee. DOE will approve the proposed amendments.

All subcommittee meeting requirements will be followed by the executive committee except where noted in the following sections.

\subsection{Executive Committee Chair}

The executive committee will have one chairperson. The executive committee chair shall serve as the principal spokesperson for the executive committee and shall preside at all meetings of the executive committee. The chair verifies the review and approval of all reports and other documents from the subcommittee meetings. The chair is also responsible for the meeting agenda and overseeing subcommittee chairs.

\subsection{Executive Committee Responsibilities}

The executive committee has the following responsibilities:

- Report the progress of each subcommittee meeting

- Approve the subcommittee designations of comments via the summary of changes

- Review and recommend changes and approve the SWS Maintenance Procedures

- Oversee crosscutting issues between various sections of the SWS to ensure document consistency

- Recommend public statements on approved updates. 


\section{Summary Report}

A summary report is issued by the facilitator within six months of the conclusion of an in-person maintenance event. The report shall be posted on the SWS online tool. The percentage change of the SWS will be provided in the online tool (i.e., the number of details changed divided by the total number of details in the SWS). The report shall follow approximately the outline below.

1. Executive summary

2. Summary of attendees

3. Publication and openness of event

4. Comments and their resolutions (spreadsheet)

5. Next SWS maintenance event preparation

6. Other actions taken

7. Recommendations for future actions

8. Appendix
A. Meeting minutes from executive committee
B. Meeting minutes from subcommittees. 


\section{Glossary}

Balance

Dominance

Facilitator

Maintenance

SWS maintenance

event

Standard
A condition existing when: (a) no single interest category (i.e., sector, company, region, and so on) constitutes more than one-third of the membership of a consensus body dealing with safety; or (b) no single interest category constitutes a majority of the membership.

A position or exercise of dominant authority, leadership, or influence by reason of superior leverage, strength, or representation to the exclusion of fair and equitable consideration of other viewpoints.

The organization that facilitates the SWS maintenance event with responsibilities, including organizing the meetings, the SMEs, and records of the meeting.

Maintenance of a standard for which procedures have been established to consider and process proposed changes as they are received.

Cycle of receiving comments on the SWS, convening subject matter experts in subcommittees to review the comments with overarching decisions made by the executive committee, and making approved changes to the SWS content.

A document established by authority or rule that defines properties, processes, dimensions, materials, relationships, procedures, concepts, nomenclature, or test methods for rating purposes. Adherence to due process in the development of a standard and achievement of consensus are conditions of approval. 


\section{Appendix A: SWS Maintenance SME Selection}

The following is the general overview of the ranking criteria for new SWS maintenance committee members. The requirements for participation include:

- Experience with the Guidelines for Home Energy Professionals Project

- Experience within the field of residential home energy upgrades.

Using the list of qualified SMEs, evaluators will use a quantitative process as described below to rank the applicants. Ideally, this quantitative process will show strong candidates for committee chairs and members for future SWS maintenance events.

Upon completion of the quantitative review process, the top candidates will be reviewed qualitatively to ensure they meet the required criteria. The qualitative review will involve reading through an applicant's resume and verifying information when appropriate.

\section{SWS Maintenance SME Ranking Criteria}

1. Rank candidates using the following criteria for up to 10 points (pts)

A. If the candidate has been practicing in the residential energy upgrade industry:

i. Zero to three years $=0$ pts

ii. Four years to nine years $=1 \mathrm{pt}$

iii. 10 years or more $=2 \mathrm{pts}$

B. If the candidate is currently working within $\mathrm{WAP} /(\mathrm{Wx})$ programs:

i. Programmatic position, production manager $=0 \mathrm{pts}$

ii. Crew Leader or Retrofit Installer experience $=1 \mathrm{pt}$

iii. Quality Control Inspector, Energy Auditor, Trainer=1 pt

C. If the candidate has previously participated in the Guidelines project:

i. Has an SWS account $=1 \mathrm{pt}$

ii. Participated in a committee, in-person event, or webinar $=1 \mathrm{pt}$

D. If the candidate made comments to the SWS details or specification:

i. Any comment on the $\mathrm{SWS}=1 \mathrm{pt}$

E. If the candidate holds a professional certificate or credential:

i. Guidelines for Home Energy Professionals certification=1 pt

ii. If the candidate has two or more additional certificates $=1 \mathrm{pt}$

F. If the candidate is involved in any other professional committees or technical committees (e.g., ASHRAE, RESNET, BPI):

i. Previous or current committee member $=1 \mathrm{pt}$ 
2. Separate full list into two lists as indicated by interest: subcommittee chairs and subcommittee members. Note: a candidate may appear on both lists.

A. For subcommittee chairs:

i. If the candidate indicates leadership in their resume, assign the following:

1. If leadership position in other professional society, assign 2 pts

2. If other form of leadership position, assign $1 \mathrm{pt}$

3. Create a group of up to three or more individuals for the subcommittee using the ranking above and the following criteria. Selection of individuals shall be from the qualified applicant list for the designated topic area of the SWS resource category and shall be done in as random a manner as possible.

A. No more than one individual per employer

B. No more than two individuals per region

i. West: includes CA, NV, ID, MT, WY, UT, CO, SD, \& ND

ii. South: includes AZ, NM, TX, OK, AR, \& LA

iii. Southeast: includes NC, SC, GA, FL, AL, MS, KY, \& TN

iv. Northwest: includes WA \& OR

v. Northeast/east: includes VA, WV, DC, MD, DE, PA, NJ, NY, RI, CT, $\mathrm{MA}, \mathrm{VT}, \mathrm{NH}, \& \mathrm{ME}$

vi. Midwest: includes $\mathrm{KS}, \mathrm{MO}, \mathrm{NE}, \mathrm{IA}, \mathrm{MN}$, WI, MI, IL, IN, OH

Three to twelve SMEs per category is stipulated in the SWS Maintenance Procedures; the target size for each subcommittee is eight to ten, including the chair. 


\section{Appendix B: Record of Changes to SWS Maintenance Charter}

Record of Changes to SWS Maintenance Charter

Table B-1. Record of Changes to SWS Maintenance Charter

\begin{tabular}{|l|l|l|}
\hline Revision & Changes & Date \\
\hline Preliminary Draft & Original Release & $02 / 03 / 2014$ \\
\hline Version 1.1 & $\begin{array}{l}\text { Combined and revised Charter and Procedures } \\
\text { Documents for clarity }\end{array}$ & $06 / 26 / 2018$ \\
\hline Version 1.2 & $\begin{array}{l}\text { Revised to account for transition to five-year } \\
\text { maintenance cycle }\end{array}$ & $02 / 07 / 2020$ \\
\hline & & \\
\hline & & \\
\hline
\end{tabular}

